J. Dairy Sci. 92:499-505

doi:10.3168/jds.2008-1007

(c) American Dairy Science Association, 2009.

\title{
Effects of body weight and nutrition on histological mammary development in Holstein heifers
}

\author{
K. M. Daniels, ${ }^{\star}$ M. L. McGilliard, ${ }^{*}$ M. J. Meyer,† M. E. Van Amburgh,† A. V. Capuco,‡ and R. M. Akers ${ }^{\star 1}$ \\ *Department of Dairy Science, Virginia Polytechnic Institute and State University, Blacksburg 24061 \\ †Department of Animal Science, Cornell University, Ithaca, NY 14853 \\ ¥Bovine Functional Genomics Laboratory, Animal and Natural Resources Institute, Agricultural Research Service, USDA, Beltsville, MD 20705
}

\section{ABSTRACT}

Our objective was to determine the effects of rate of gain and body weight (BW) on development of the mammary parenchyma. Mammary tissue samples were collected from heifers $(\mathrm{n}=72)$ reared on 1 of 2 dietary treatments (restricted, $650 \mathrm{~g} / \mathrm{d}$ of daily gain; or elevated, $950 \mathrm{~g} / \mathrm{d}$ of daily gain) and slaughtered at $100,150,200,250,300$, or $350 \mathrm{~kg}$ of BW. Mammary samples were excised, preserved, prepared for histology, and stained with hematoxylin and eosin. Digital images of tissue sections were captured for analysis. Tissue areas occupied by the interlobular and intralobular stroma, epithelium, and lumen were measured $\left(\mu \mathrm{m}^{2}\right)$. The numbers of epithelial and luminal structures per image were tabulated to measure the complexity of ductal development. Mean percentages of mammary parenchyma occupied by the interlobular stroma, epithelium, lumen, and intralobular stroma were 29, 20, 7, and $43 \%$, respectively. Percentage of area occupied by the intralobular stroma was affected by BW and was lower for 100-kg heifers compared with heifers $200 \mathrm{~kg}$ and heavier ( $33 \pm 4$ vs. $46 \pm 4$ ), but the percentage of area occupied by other tissue elements did not differ by $\mathrm{BW}$ or treatment, nor was there an interaction. However, the numbers of both epithelial ( $8.3 \pm 4$ vs. $47 \pm$ 4 ) and luminal-containing ( $6 \pm 4$ vs. $38 \pm 4$ ) structures per image increased markedly between 100 and $350 \mathrm{~kg}$ of BW, irrespective of diet. For heifers slaughtered between 100 and $350 \mathrm{~kg}$ of BW, alterations in the rate of gain between 650 and $950 \mathrm{~g} / \mathrm{d}$, accomplished by feeding varying amounts of the same diet, had no significant effect on tissue characteristics or the pattern of mammary parenchymal development. These data emphasize the importance of BW and age in determining developmental characteristics of the heifer mammary parenchyma and suggest that the rate of gain per se has a minimal impact on histological development, and thus do not

Received January 9, 2008.

Accepted October 15, 2008.

${ }^{1}$ Corresponding author: rma@vt.edu support the hypothesis that rate of gain has a direct negative impact on ductal development.

Key words: heifer, histology, mammary, nutrition

\section{INTRODUCTION}

Nutrition is an important factor that influences peripubertal heifer mammary growth. Dairy producers, to lower the age at first calving and the period of nonproductive life of their replacement animals, often maintain replacement heifers on high-gain diets (BW gains $>700 \mathrm{~g} / \mathrm{d}$ ) during the prepubertal period. This practice, although known to increase rates of skeletal and BW growth, may reduce development of the mammary ductal epithelium (Sejrsen and Purup, 1997). With diminished development of the ductal epithelium, reductions in secretory tissue development and milk yield can occur (Swanson, 1960; Little and Kay, 1979; Sejrsen et al., 2000). This is because the mammary secretory epithelium (alveoli), which develops during gestation, depends on ducts that have developed in earlier life. Thus, the peripubertal period has often been characterized as a critical period for the early mammary development of dairy heifers. Nonetheless, the impact of nutrition on prepubertal mammary growth and future milk production remains controversial (Capuco et al., 2003; Meyer et al., 2006a,b). In part, this is because of interacting factors. For example, if animals are compared at equivalent BW, then animals that are reared with greater rates of gain inherently are younger at the time of sample collection. If animals are compared at equivalent ages, then BW of animals reared for slower rates of gain are reduced. In addition, questions related to the effect of diet composition on mammary development can be more readily evaluated if the diets being compared can be formulated to yield equal rates of gain.

The evaluation of histological features has been a long-standing technique used by many in the field of mammary biology to study tissue growth and development under both normal and experimental conditions. The use of histological observations to demonstrate 
changes in the mammary development of ruminants has a long history (Turner, 1952; Wallace, 1953). We sought to determine the effects of rate of gain and BW on histological development of the mammary gland in Holstein heifers by measuring tissue areas occupied by epithelial cells, the ductal luminal area, and the intraand interlobular connective tissues. We sought to evaluate the complexity of ductal development by tabulating the number of epithelial structures and the number of lumen-containing structures per histological image. We reasoned that mammary ducts with many budlike branches, when sectioned, would exhibit multiple "epithelial islands" within the image. Similarly, increased numbers of lumen-containing structures within an image would indicate the development of progressively more complex structures. Our hypothesis was that rearing heifers for a rapid rate of gain would impair mammary ductal development and that this impairment would be evident in these animals, which would have a reduced tissue area occupied by epithelial cells or a correspondingly greater stromal tissue area, or both. We hypothesized that rapid rearing would impair mammary ductal development so that these animals would exhibit fewer ducts as well as less complex ducts (e.g., fewer branches). This would be expressed by images of tissues from these heifers exhibiting fewer epithelial structures, lumen-containing structures, or both.

\section{MATERIALS AND METHODS}

\section{Animals and Treatments}

The tissue samples used were from animals that were purchased within 1 wk of age from commercial dairy farms surrounding Ithaca, New York, and processed at Cornell University, as reported in previous papers by Meyer et al. (2006a,b). Briefly, heifers $(\mathrm{n}=78)$ were randomly assigned to 1 of 2 dietary treatments [restricted $(\mathbf{R}), \mathrm{n}=36$; or elevated $(\mathbf{E}), \mathrm{n}=36$ ], or a baseline group (6 heifers, $45 \mathrm{~kg}$ of BW). Within treatments, equal numbers of heifers were randomly assigned to each of 6 slaughter weights $(100,150,200,250,300$, or $350 \mathrm{~kg}$ of BW). Six heifers per dietary treatment were slaughtered at each time point, for a total of 78 heifers (including the baseline group). Tissues from the baseline animals were not available for histological evaluation. The specific slaughter weights given above were chosen to represent periods when the mammary gland transitions from isometric to allometric growth, as well as periods within the allometric growth phase. This was based on the temporal pattern of mammary development reported by Sinha and Tucker (1969).

Heifers on the R-gain dietary treatment were fed a preweaning diet that consisted of a $22 \% \mathrm{CP}$ and $21 \%$ fat
(DM basis) milk replacer that was fed at 0.20 Mcal of gross energy $/ \mathrm{kg}$ of $\mathrm{BW}^{0.75}$. Heifers on the E-gain dietary treatment were fed a preweaning diet that consisted of a $29 \% \mathrm{CP}$ and $19 \%$ fat (DM basis) milk replacer that was fed at $0.32 \mathrm{Mcal}$ of gross energy $/ \mathrm{kg}$ of $\mathrm{BW}^{0.75}$. A $27 \% \mathrm{CP}$ calf starter was offered to animals beginning at approximately 3 wk on the study. Heifers were weighed weekly, and the amount of feed offered was adjusted so that heifers on the $\mathrm{R}$ treatment could achieve $650 \mathrm{~g}$ of ADG and heifers on the E treatment could achieve 950 $\mathrm{g}$ of ADG. From the initiation of treatment to $150 \mathrm{~kg}$, heifers were housed in individual pens in the Teaching and Research Dairy Center Greenhouse at Cornell University. On reaching $150 \mathrm{~kg}$, heifers that were assigned to heavier slaughter weights were grouped in 1 pen and individually fed via a Calan gate system (American Calan, Northwood, NH). Other details related to feeding and rearing are available in Meyer et al. (2006a).

Once heifers that were assigned to slaughter weights $\geq 250 \mathrm{~kg}$ reached $225 \mathrm{~kg}$ of $\mathrm{BW}$, blood was collected twice weekly via jugular venipuncture, and plasma progesterone concentrations were determined. Progesterone concentrations $>1 \mathrm{ng} / \mathrm{mL}$ were interpreted as evidence of a functional corpus luteum and the heifer was therefore considered pubertal. For heifers slaughtered after puberty, progesterone was evaluated to determine that these heifers were in the luteal phase of the estrous cycle at the time of sampling.

\section{Slaughter Procedure and Mammary Tissue Collection}

Heifers were weighed weekly to monitor target rates of gain. The decision to slaughter at a common BW, as opposed to a common age, was based on observations that puberty is more closely associated with BW than with a specific age (Sejrsen, 1994). Pubertal heifers were slaughtered in the luteal phase of their reproductive cycle, based on plasma progesterone concentrations.

Humane slaughter of each heifer was performed at the Department of Animal Science Abattoir at Cornell University with a captive bolt stunner, followed by exsanguination. At slaughter, the udder of each heifer was removed and bisected along the medial suspensory ligament. Tissues harvested from the midparenchymal region of 1 side of the udder were preserved and embedded in paraffin.

\section{General Staining Procedures for Microscope Slides}

Microscope slides were prepared by slicing $5-\mu \mathrm{m}$ thick sections from the paraffin-embedded tissue blocks with a microtome (Reichert-Jung Model 2040 Autocut, Lecia Microsystems, Wetzlar, Germany), and 4 or 5 
serial tissue sections from each sample were mounted on a microscope slide. Slides were stained according to the method of Brown et al. (2005). Briefly, tissue sections were deparaffinized, hydrated, stained with hematoxylin and eosin (Sigma Aldrich Chemical Co., St. Louis, MO), and dehydrated, and a coverslip was placed on the tissue.

\section{Digital Image Acquisition and Area Measurements}

Hematoxylin and eosin-stained images of mammary tissue were captured with a top-mounted digital microscope camera (Olympus DP10, Opelco, Dulles, VA) under $10 \times$ magnification. Each image was centered in an area predominantly occupied by epithelial (vs. stromal) cells. Three pictures were taken at random locations within each tissue section on the microscope slide for each heifer. Digital images were transferred to a computer and stored for subsequent analysis.

All measurements were made by using a digital image analysis program (Image-Pro Plus Version 4.5 for Windows, Media Cybernetics Inc., Silver Spring, MD). Images of a stage micrometer were taken and used to calibrate the measurement tools used as part of the software package. Each of our $10 \times$ magnification images encompassed an area of $871,820 \mu^{2}$. After pilot testing determined that variation among independent images of each tissue sample were minimal, 1 of the images from each heifer was chosen at random for further analysis. Total areas occupied by the interlobular stroma, epithelium, lumen, and intralobular stroma were determined for each image. This was achieved by using the computer mouse to outline desired structural features. The computer program recorded the area (in $\mu \mathrm{m}^{2}$ ) for each structure that was outlined; these measurements were then exported to a Microsoft Excel (Microsoft Corporation, Redmond, WA) spreadsheet, where total areas for each mammary parenchymal component were calculated via summation. The total area occupied by intralobular stroma was calculated by subtracting the total areas occupied by the interlobular stroma, epithelium, and lumen from the total area $\left(871,820 \mu \mathrm{m}^{2}\right)$. To evaluate the complexity of ductal development (i.e., degree of ductal branching), the numbers of epithelial and luminal structures in each image were tabulated and recorded.

\section{Statistical Analyses}

The main effects of diet and slaughter weight, as well as the interaction between the two were tested by using the GLM procedure (Version 8.0, SAS Institute Inc., Cary, NC). The total area occupied by the interlobular stroma, epithelium, lumen, and intralobular stroma, and the numbers of epithelial and luminal structures present were used as dependent variables. Diet was either R or E, and target slaughter weights were 100, $150,200,250,300$, or $350 \mathrm{~kg}$.

The following model statement was used: $Y_{\mathrm{ijk}}=\mu+$ $\mathrm{D}_{\mathrm{i}}+\mathrm{W}_{\mathrm{j}}+(\mathrm{DW})_{\mathrm{ij}}+\mathrm{E}_{(\mathrm{ij}) \mathrm{k}}$, where $\mathrm{Y}_{\mathrm{ijk}}$ are the dependent variables, area or percentage of tissue type; $\mu$ is the overall mean; $D_{i}$ is the fixed effect of $\operatorname{diet}(\mathrm{R}$ vs. $\mathrm{E}, \mathrm{i}$ $=1,2) ; \mathrm{W}_{\mathrm{j}}$ is the fixed effect of target weight $(\mathrm{j}=1$, ..., 6); $\mathrm{DW}_{\mathrm{ij}}$ is the effect of the interaction of diet and target weight; and $\mathrm{E}_{(\mathrm{ij}) \mathrm{k}}$ is the residual error $(\mathrm{k}=1,6$ heifers within a subclass).

Results are presented as least squares means \pm standard errors of the means. Differences were considered significant at $P<0.05$; trends were declared at $P<$ 0.10 . Orthogonal polynomial contrasts were used to test for linearity in the response of dependent variables to BW. A multivariate ANOVA was conducted to test a vector of all tissue types simultaneously. This was to determine whether the profile of tissue areas (percentages of interlobular stroma, epithelium, lumen, and intralobular stroma) differed by diet or slaughter weight. The dependent variable "total area occupied by the lumen" was removed from the model statement for multivariate ANOVA because all tissue areas totaled $100 \%$. Dietary treatment, heifer slaughter BW, and the interaction of dietary treatment with heifer slaughter BW were tested for all tissue characteristics simultaneously.

\section{RESULTS}

Actual slaughter weights of the animals and actual daily gains of the animals are discussed in detail by Meyer et al. (2006a,b). The percentages of parenchymal area occupied by the interlobular stroma, epithelium, lumen, and intralobular stroma did not significantly differ by BW or dietary treatment, nor was there an interaction between dietary treatment and BW for these variables (Table 1). In contrast, the area occupied by intralobular stroma was lower in 100- and $150-\mathrm{kg}$ heifers compared with heavier heifers $(33.1 \pm 2.4$ and 40.3 \pm 3.0 vs. $45.1 \pm 0.9$ ) but was unaffected by dietary treatment. Thus, clusters of ducts were more closely arranged within individual lobules. In the multivariate ANOVA, except for intralobular stroma, there were no overall effects of dietary treatment, heifer BW, or the interaction between dietary treatment and $\mathrm{BW}$ on the array of tissue percentages measured. Overall, the mean percentages of mammary parenchyma occupied by the interlobular stroma, epithelium, lumen, and intralobular stroma were $29,20,7$, and $43 \%$, respectively. Figure 1 identifies components of the heifer mammary parenchyma. The numbers of epithelial and luminal structures differed by BW, irrespective of dietary treat- 


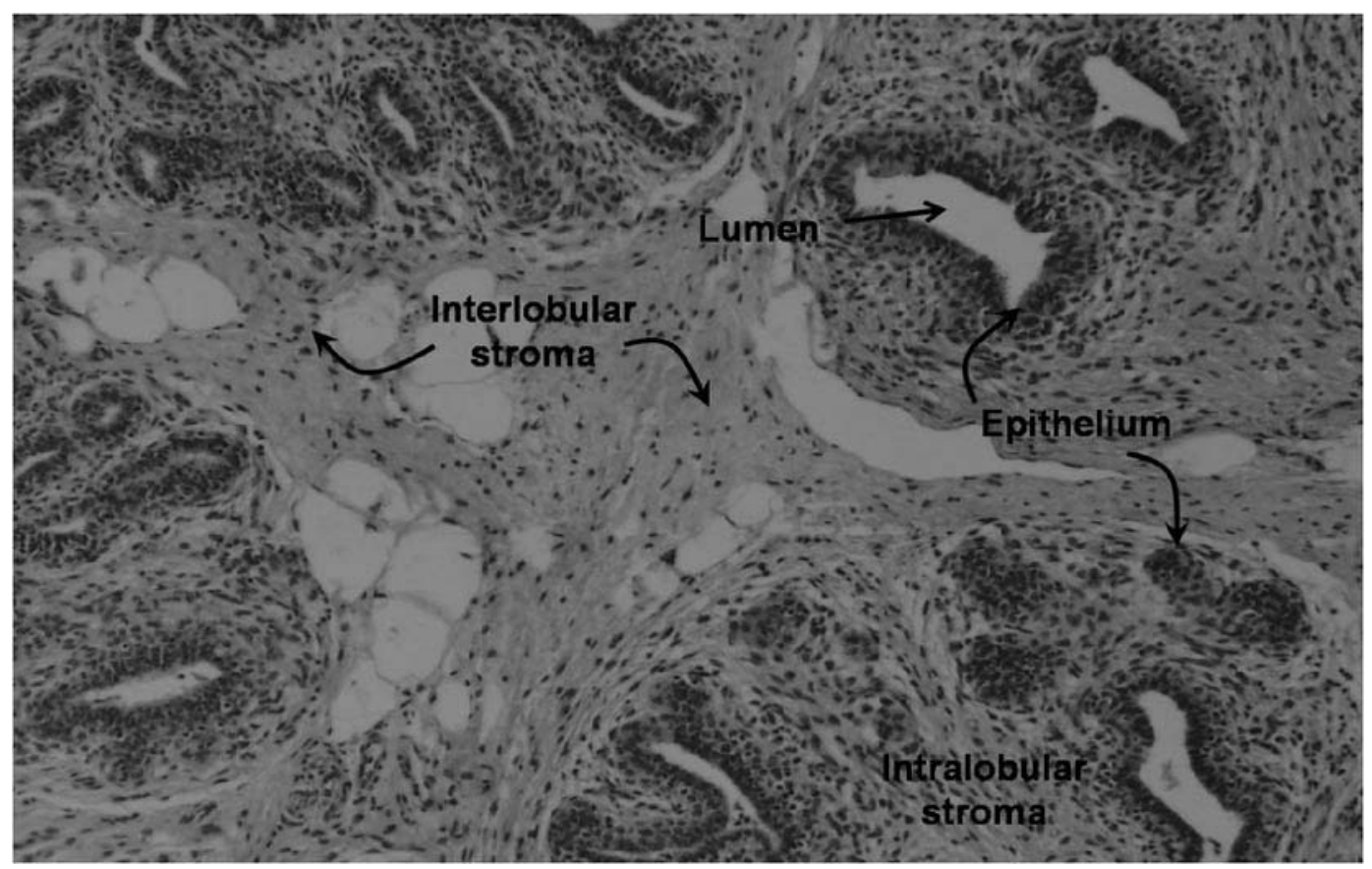

Figure 1. Representative image of heifer mammary tissue at $10 \times$ magnification stained with hematoxylin and eosin.

ment (Figure 2). There were a trend $(P<0.10)$ for different numbers of epithelial and luminal structures per field in R-group heifers (Figure 3). The numbers of epithelial and luminal structures increased linearly with increased heifer BW $(P<0.001, P<0.001$, respectively; Figure 4).

\section{DISCUSSION}

The study demonstrated that for heifers slaughtered between 100 and $350 \mathrm{~kg}$ of BW, alterations in the rate of gain between 650 and $950 \mathrm{~g} / \mathrm{d}$, accomplished by feed- ing varying amounts of the same diet, had no significant effect on tissue characteristics or the complexity of mammary parenchymal development. It is important to appreciate that histological evaluations did not measure total mammary ductal development in the udder, but more specifically characterized the degree and pattern of ductal development. Nevertheless, there was no effect of rate of gain on various measures of mammary parenchymal growth or biochemical composition of the mammary parenchyma in these heifers when age was taken into account in analysis of the data (Meyer et al., 2006a,b).

Table 1. Histological components of heifer mammary parenchyma for animals fed 1 of 2 diets and sacrificed at 1 of 6 BW

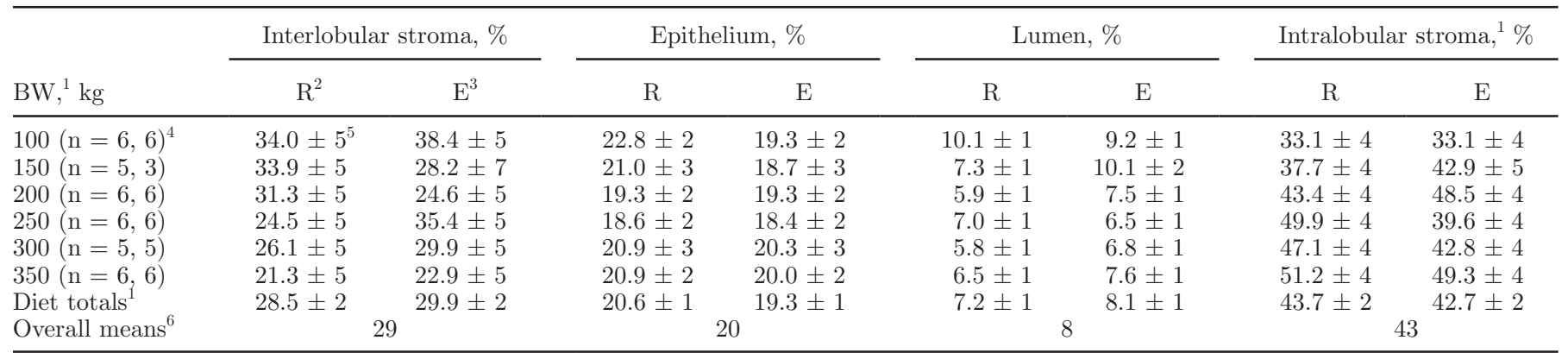

${ }^{1}$ There were no differences in the significance of main effects (dietary treatment and BW) or in their interaction for the variables listed, with the exception of a significant effect of BW on the percentage of intralobular stroma $(P=0.003)$.

${ }^{2}$ Restricted dietary treatment $(650 \mathrm{~g} / \mathrm{d}$ of ADG).

${ }^{3}$ Elevated dietary treatment $(950 \mathrm{~g} / \mathrm{d}$ of ADG).

${ }^{4}$ Number of animals per diet within each BW group: restricted diet, and elevated diet, respectively.

${ }^{5}$ Listed values are least squares means \pm SEM.

${ }^{6}$ Overall means for each variable across all dietary treatments and BW. 
By comparison, it is important to consider results from the limited number of experiments that have evaluated the impact of prepubertal nutrition on the histology of mammary gland development. Capuco et al. (1995) evaluated the impact of corn silage and alfalfa silage diets fed to achieve targeted rates of gain of 750 or $1,000 \mathrm{~g} / \mathrm{d}$. A high rate of gain reduced mammary parenchyma at puberty only in heifers fed the corn silage diet. Furthermore, histological evaluation indicated that the percentage of parenchymal area occupied by the epithelium was reduced and the area occupied by adipocytes (primarily interlobular stroma) was concomitantly increased in heifers on the high-corn diet. Increased adiposity of the parenchyma was associated with decreased epithelium, but data suggested that the effect was not an inhibition of the primary ducts, but of the extent of ductal branching. This suggests the importance of diet composition, perhaps independent of rate of gain.

By contrast, Sejrsen et al. (1982) found that pre- and postpubertal Holstein heifers fed appropriate quantities of the same ration achieved desired rates of gain. Heifers in the R group gained $613 \mathrm{~g} / \mathrm{d}$, and the ADG for heifers with ad libitum access was $1,218 \mathrm{~g} / \mathrm{d}$. Rate of gain did not affect the percentage of parenchyma occupied by epithelial cells, connective tissue, adipocytes, or ductal lumen in either pre- or postpubertal heifers. This was despite an apparent inhibition of mammary parenchymal mass when assessed at a common BW but at a different age. However, this study did not evaluate the characteristics of ductal development.

In an experiment designed to evaluate the impact of nutrition during 2 periods of early mammary development in heifers (2 to 8 wk of age and 8 to 14 wk of age), Brown et al. (2005) concluded that the feeding amount did not significantly affect the percentage of epithelial tissue in mammary parenchyma. Nevertheless, dietary treatment may have induced both obvious (mass and DNA) and subtle changes (altered ductal branching or extracellular matrix deposition) in the tissue. Increasing energy and protein intake from 2 to 8 wk of age increased mammary parenchymal growth (mass and DNA), whereas increased nutrition from 8 to $14 \mathrm{wk}$ of age did not influence mammary parenchymal growth, but promoted deposition of fat within the parenchyma and the mammary fat pad. Although parenchymal growth was promoted by increased nutrition at 2 to 8 wk, the treatment appeared to enhance the development of more mature ducts (larger lumens) so that proliferation of this epithelium (assessed by Ki67 labeling) may have been reduced during subsequent development.

Across all treatments, Brown et al. (2005) determined mammary parenchymal composition by tissue area as approximately $20 \%$ epithelium, $8 \%$ lumen, and
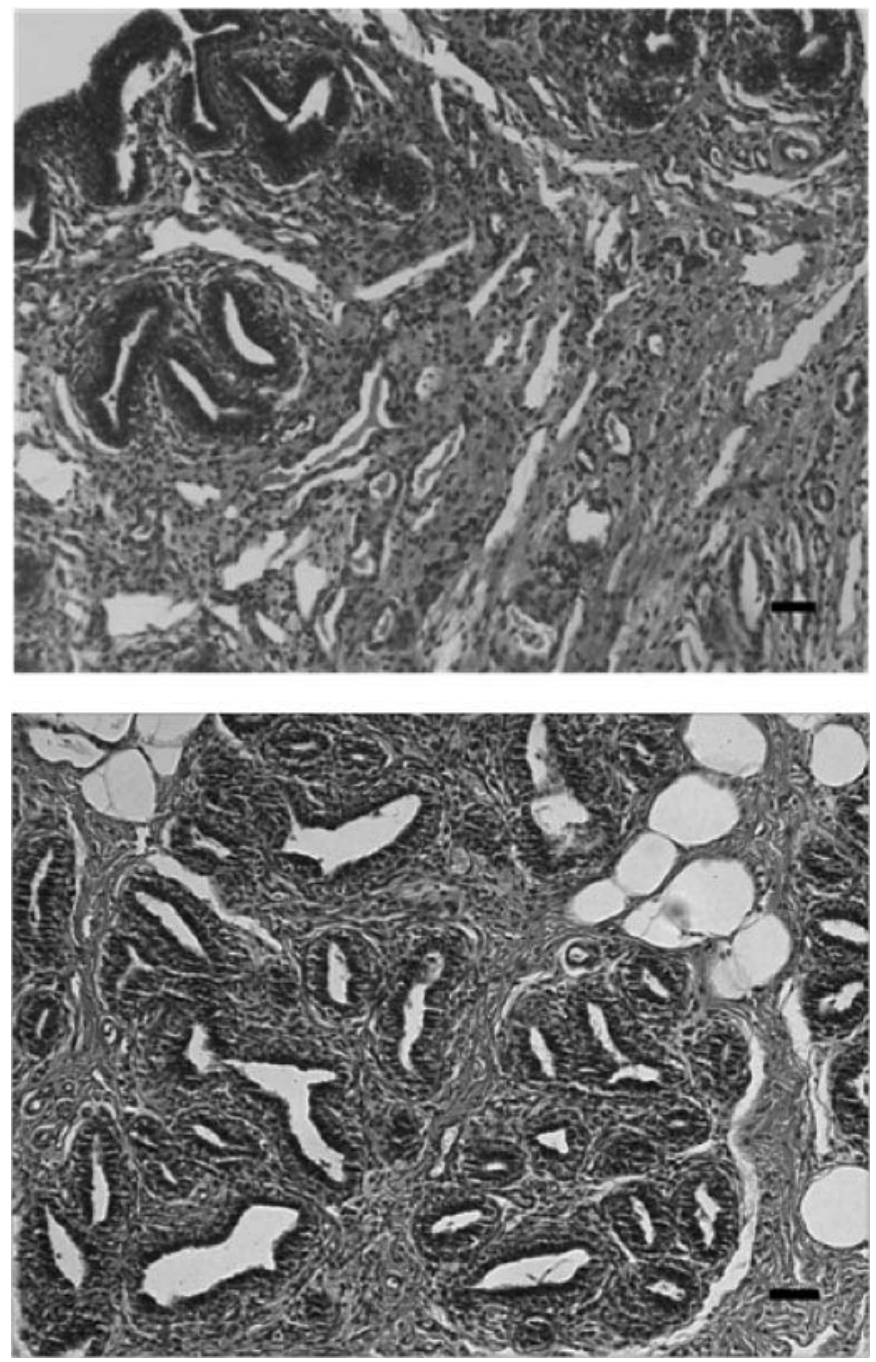

Figure 2. Image of mammary tissue from a 100-kg heifer (upper panel) and a 350-kg heifer (lower panel). The bar in both images equals $50 \mu \mathrm{m}$. Differences in tissue complexity are illustrated by the marked difference in the number of epithelial structures per field.

$72 \%$ inter- and intralobular stroma. These values are supported by those reported in the present experiment. Similarly, Capuco et al. (1995) reported 19\% epithelium, $48 \%$ connective tissue, and $33 \%$ adipocytes for heifers in all treatments, with the exception of those on the high-gain corn silage treatment, in which heifers exhibited inhibited parenchymal growth and averaged $12 \%$ epithelium, $37 \%$ connective tissue, and $51 \%$ adipocytes. Sejrsen et al. (1982) reported that at the end of the allometric mammary growth phase (approximately 250 to $280 \mathrm{~kg}$ of BW), Holstein heifer mammary parenchyma contained approximately $10 \%$ epithelial cells, $50 \%$ connective tissue, 30 to $40 \%$ adipocytes, and 2 to $3 \%$ ductal lumen. Data for the current experiment provide the strongest developmental evidence to date 
that rate of gain per se does not influence the nature of mammary parenchymal growth. However, the data of Capuco et al. (1995) suggest that diets that promote excessive body and mammary fat deposition may inhibit mammary parenchymal growth and thereby alter ductal architecture.

Overall, the E rate of BW gain imposed in the current experiment had no apparent deleterious effects on growth or composition of the mammary parenchyma. Meyer et al. (2006b) previously reported on differences in the proportions of mammary epithelial cells actively dividing, attributable to dietary treatment or heifers with BW greater than $100 \mathrm{~kg}$, or both. Based on the experiments conducted thus far with mammary tissues from this specific group of heifers (Meyer et al., 2006b), there were neither ill effects nor advantageous biological effects of maintaining heifers on an elevated lifetime plane of nutrition (target lifetime BW gain of $950 \mathrm{~g} / \mathrm{d}$ ). Data for the present study lead us to speculate that many reported rate of gain effects on peripubertal mammary gland development might often be attributed to experimental designs that elicited treatment effects that result from comparing heifers of different ages and hence different stages of mammary development. Nonetheless, it is important to appreciate that there are likely nutritionally mediated effects that can dramatically affect heifer mammary development and that these responses could likely interact in unexpected ways with other management factors. Thus, these results must be viewed within the confines of this experimental design (i.e., feeding different amounts of the same diet to achieve different rates of gain).

Diets that would differentially affect secretion of mammogenic hormones (growth hormone or estrogen) or local mammary tissue expression of mammogenic hormones and growth factors or their receptors would be expected to alter mammary development. Thus, particular caution is necessary when differences in rate of gain are achieved by feeding diets with different compositions. Certainly, dietary treatments that influence ovarian or pituitary function are likely to affect mammary development. Clearly, mammary cells of prepubertal ruminants are sensitive to estrogen, progesterone, growth hormone, and other mammogenic agents (McFadden et al., 1990; Woodward et al., 1993; Maple et al., 1998). Even with an equal proliferation rate, accelerated heifer growth rates may ultimately reduce mammary development at the conclusion of the allometric phase of prepubertal development because of earlier puberty and a shortening of the period of allometric mammary growth. A key issue is whether a decrease in mammary parenchymal mass is permanent.

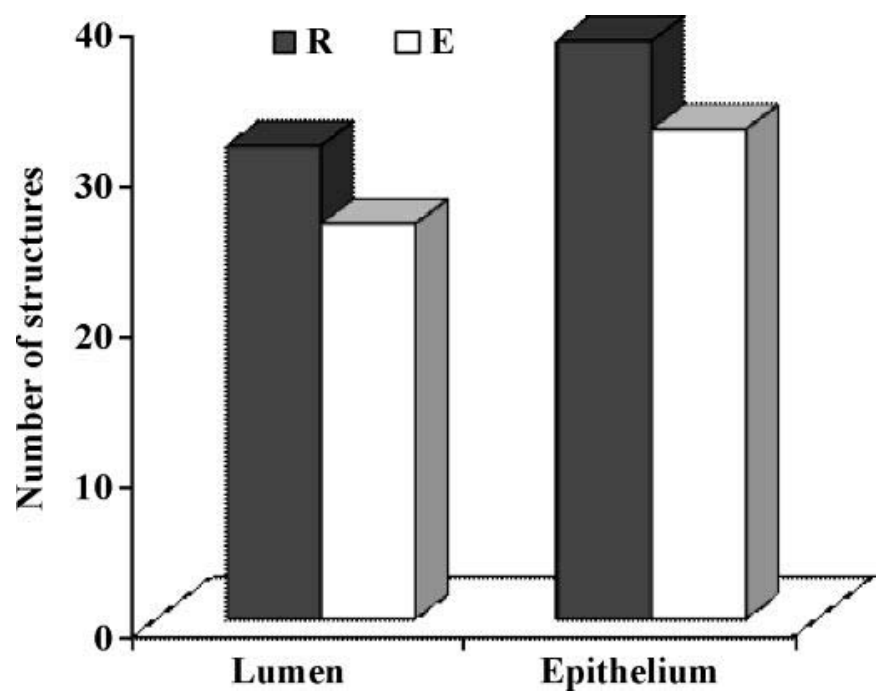

Figure 3. Number of epithelial and luminal structures present in an $871,820 \mu \mathrm{m}^{2}$ area of the mammary parenchyma taken from heifers reared on either an elevated (E; $950 \mathrm{~g} / \mathrm{d}$ of ADG; $\mathrm{n}=32$; open bars) or a restricted ( $\mathrm{R} ; 650 \mathrm{~g} / \mathrm{d}$ of $\mathrm{ADG} ; \mathrm{n}=34$; filled bars) diet across all slaughter weights. Values shown are least squares means for epithelial (SEM 2.9 and 2.8 for E and R, respectively) and luminal structures (SEM 2.5 and 2.4, for E and R, respectively); values tended to differ by diet $(P<0.1$, luminal; $P<0.1$, epithelial).

In the present study, the number of epithelial and luminal structures present in the mammary parenchyma increased with increasing BW (Figures 2 and 4). These measurements are believed to be indicators of mammary parenchymal tissue complexity. For example, with increasing BW (maturity), there is undoubtedly more side-branching of mammary ducts to create the "ductal tree" of the mammary epithelium that will eventually give rise to alveoli. As the mammary epithelial tissue expands via ductal branching and elongation from the gland cistern to the more dorsal fat pad, the surrounding stroma (which includes the fibroblasts, adipocytes, endothelial cells, and extracellular matrix components) must be remodeled. A future developmental evaluation of extracellular matrix protein deposition in heifers in the present study would provide valuable information regarding ductal elongation and branching.

In summary, we found no histological differences in mammary parenchymal composition in tissues taken from Holstein heifers reared on 1 of 2 planes of nutrition and slaughtered at varying BW. These findings support the previously reported absence of effects on mammary epithelial cell proliferation and mammary parenchymal DNA accretion rates in these heifers.

\section{CONCLUSIONS}

For heifers slaughtered between 100 and $350 \mathrm{~kg}$ of BW, alterations in the rate of gain between 650 and 950 

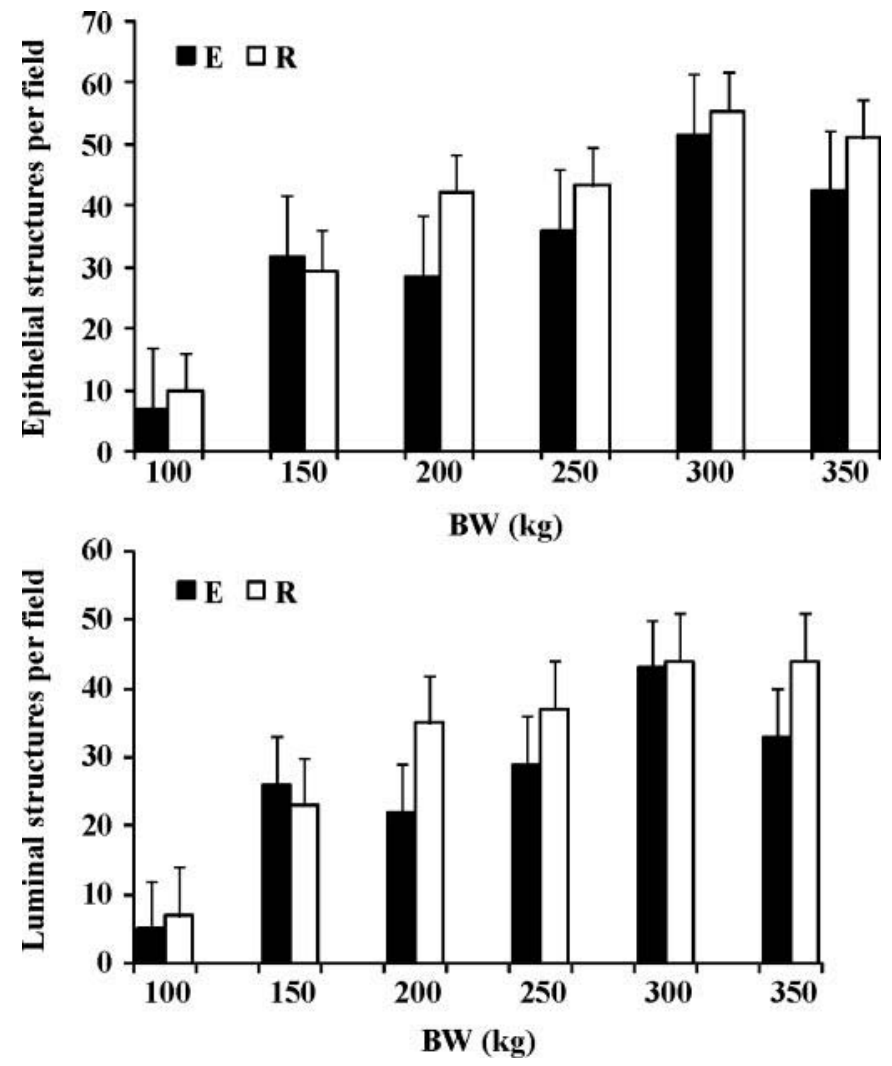

Figure 4. Number of epithelial (upper panel) and luminal structures (lower panel) present per image $\left(871,820 \mu \mathrm{m}^{2}\right.$ of mammary parenchyma) in tissue sections from heifers slaughtered at different BW $(100,150,200,250,300$, or $350 \mathrm{~kg}$ of $\mathrm{BW})$. Values are least squares means for heifers fed either a restricted $(\mathrm{R})$ or elevated $(\mathrm{E})$ diet. The linear trends for changes in the number of structures per field were significant $(P<0.001)$.

$\mathrm{g} / \mathrm{d}$, accomplished by feeding varying amounts of the same diet, had no effect on the complexity of mammary parenchymal development. Our hypothesis, that rapid rate of gain per se would impair either the degree or complexity of ductal development, was not supported by the data.

\section{ACKNOWLEDGMENTS}

The authors thank P. Boyle (Virginia Tech) for her assistance with histology procedures. We also extend our thanks to J. McFadden, M. Miller, D. Shaw, B. Berggren-Thomas, and J. Kelsey-Mills (Cornell Univer- sity) for their assistance with animal care and tissue collection.

\section{REFERENCES}

Brown, E. G., M. J. VandeHaar, K. M. Daniels, J. S. Liesman, L. T. Chapin, J. W. Forrest, R. M. Akers, R. E. Pearson, and M. S. Weber Nielsen. 2005. Effect of increasing energy and protein intake on mammary development in heifer calves. J. Dairy Sci. $88: 595-603$.

Capuco, A. V., R. Erdman, G. Dahl, M. Meyer, and M. Van Amburgh. 2003. Heifer nutrition prepubertal growth and development. Pages 102-115 in Proc. 50th Maryland Nutr. Conf. Feed Manufact. and 1st Mid-Atlantic Nutr. Conf. University of Maryland, College Park.

Capuco, A. V., J. J. Smith, D. R. Waldo, and C. E. Rexroad Jr. 1995. Influence of prepubertal dietary regimen on mammary growth of Holstein heifers. J. Dairy Sci. 78:2709-2725.

Little, W., and R. M. Kay. 1979. The effect of rapid rearing and early calving on subsequent performance of dairy heifers. Anim. Prod. $29: 131-142$.

Maple, R. L., R. M. Akers, and K. Plaut. 1998. Effects of steroid hormone treatment on mammary development in prepubertal heifers. Domest. Anim. Endocrinol. 15:489-498.

McFadden, T. B., T. E. Daniel, and R. M. Akers. 1990. Effects of plane of nutrition, growth hormone and unsaturated fat on mammary growth in prepubertal lambs. J. Anim. Sci. 68:3171-3179.

Meyer, M. J., A. V. Capuco, D. A. Ross, L. M. Lintault, and M. E. Van Amburgh. 2006a. Developmental and nutritional regulation of the prepubertal heifer mammary gland: I. Parenchyma and fat pad mass and composition. J. Dairy Sci. 89:4289-4297.

Meyer, M. J., A. V. Capuco, D. A. Ross, L. M. Lintault, and M. E. Van Amburgh. 2006b. Developmental and nutritional regulation of the prepubertal bovine mammary gland: II. Epithelial cell proliferation, parenchymal accretion rate, and allometric growth. J. Dairy Sci. 89:4298-4304.

Sejrsen, K. 1994. Relationships between nutrition, puberty, and mammary development in cattle. Proc. Nutr. Soc. 53:103-111.

Sejrsen, K., J. T. Huber, H. A. Tucker, and R. M. Akers. 1982. Influence of nutrition on mammary development in pre- and postpubertal heifers. J. Dairy Sci. 65:793-800.

Sejrsen, K., and S. Purup. 1997. Influence of prepubertal feeding level on milk yield potential of dairy heifers: A review. J. Anim. Sci. 75:828-835.

Sejrsen, K., S. Purup, M. Vestergaard, and J. Foldager. 2000. High body weight gain and reduced bovine mammary growth: Physiological basis and implications for milk yield potential. Domest. Anim. Endocrinol. 19:93-104.

Sinha, Y. N., and H. A. Tucker. 1969. Mammary development and pituitary prolactin level of heifers from birth through puberty and during the estrous cycle. J. Dairy Sci. 52:507-512.

Swanson, E. W. 1960. Effect of rapid growth with fattening of dairy heifers on their lactational ability. J. Dairy Sci. 43:377-387.

Turner, C. W. 1952. The Mammary Gland. Lucas Bros., Columbia, MO.

Wallace, C. 1953. Observations on mammary development in calves and lambs. J. Agric. Sci. 43:413-421.

Woodward, T. L., W. E. Beal, and R. M. Akers. 1993. Cell interactions in initiation of mammary epithelial proliferation by oestradiol and progesterone in prepubertal heifers. J. Endod. 136:149-157. 